\title{
The features of using the interactive museum expositions in modern exhibition practice
}

\author{
T. O. Behal
}

Kyiv National University of Culture and Arts, Kyiv, Ukraine
Corresponding author. Email:_tetiana.berezniuk@gmail.com

Paper received 09.04.21; Accepted for publication 27.04.21.

https://doi.org/10.31174/SEND-HS2021-254IX46-03

\begin{abstract}
The article analyzes the characteristic features of the interactive museum exposition as an integral part of the museum space. The main factors influencing the development and improvement of the modern museum exposition in general are substantiated. Based on the analysis of exposition solutions of European museums, the main models of multimedia technologies that can be used in the design of interactive museum expositions are proposed.
\end{abstract}

Keywords: museum exposition, interactive museum exposition, multimedia technologies, interactive exhibits.

Introduction. The modern museum ceases to be a common place for storing objects, their display, research and storage. Its role and significance is greatly expanded. Today, the museum is becoming a kind of communication platform, which is a specific process of communication a visitor with a guide, a visitor with exhibits, visitors to each other. In our opinion, in order to ensure the highest quality communication process, the museum, in addition to traditional means - excursions, lectures, seminars, videos - should use modern communication channels. One of the types of such communication channels is interactive museum expositions. The introduction of multimedia and interactive technologies in the museum space is a topic that is gaining popularity and, like any developing museum practice, has a number of debatable issues. This is the relevance of this study.

A brief overview of publications on the topic. Scientists A. Vinogradov [4], O. Vaneeva [2], A. Chala [7], N. Akoeva [1], L. Vasilieva [3] and others carried out thorough research of interactive museum expositions and multimedia technologies in the exposition space of the museum. A. Vinogradov explores the interactive approach in the formation of a modern exhibition. The researcher actualizes the topic of interactive expositions by considering the activities of specific schools, studios, architects and designers, but does not consider the issue of interactivity in the classical museum in detail. N. Akoeva considers interactive methods of working with the museum exposition in her article. O. Vaneeva focuses on the integrated use of interactive technologies within the museum space. Both L. Vasilieva and A. Chala study the interactivity of the exhibition environment as a trend of modern culture. However, there is still a lack of research that would reveal the essential features of interactive museum exhibits and the peculiarities of their application in modern exhibition practice.

Objective. The purpose of the publication is to analyze and substantiate the features of the use of interactive museum exhibits in modern exhibition practice and to determine the priority areas of the development of the exhibition environment as a whole. The source base of the study is online museums, websites, and virtual exhibitions of the world's leading museums.

Materials and methods. The method of analysis and synthesis was used during the study. On the example of the analysis of interactive exposition decisions of the
European museums the innovative methods of construction of a museum exposition were developed and offered. The method of synthesis allowed to consider the interactive museum exposition in its entirety, in a single connection of its parts and to substantiate its significance and role in the modern cultural space in general.

Results and discussion. Today in the conditions of the active development of world communication processes the need to present heritage at the national and world levels comes to the fore. Exposition and exhibition activities are one of the most dynamic tools for the presentation of cultural achievements not only in the museum sphere. For example, the most popular economic trend today is the holding of various exhibitions and fairs, which are designed to promote the exhibits, a certain idea, and scientific, technical and technological renewal. A museum exhibition is a museum exposition that is created for a short time. It allows museums to acquaint visitors with the available collections of historical and cultural monuments, as well as to display objects from other (including foreign) museums and private collections. Museum exhibition is a complex that requires time, energy and professionalism of many people. Effective planning, resource management, research and interpretation, collection preservation, marketing, merchandising, design, public programs, publications and fundraising contribute to the museum's mission. An exhibition is successful when it intellectually and emotionally engages its visitors. Creation and design of museum expositions, both permanent and temporary (exhibition) is a complex and multi-stage process. Often the design of the exhibition brings together specialists of different profiles - museologists, architects, artists, designers, psychologists, consultants on specific issues. This allows creating a quality new product, making the exhibition understandable, interesting and accessible to all types of museum audiences.

However, today, thanks to the use of multimedia technologies, smartphones and personal computers, it is not necessary to visit art exhibitions, auctions, art fairs, etc. Works of art can be viewed using the world's international Internet portals (EUROPEANA, Smart history), online museums and more. They allow viewing the collections and cultural heritage of all museums around the world. Therefore, considering the traditional museum exposition, the modern visitor, in our opinion, often has to face the problem of "information loneliness" in the museum. If a 
visitor does not receive information that interests him immediately, he later forgets about it and thus receives a low-quality museum product or museum service. However, people come to the museum not only for information, but also for authenticity and atmosphere. In addition to creating "immersion zones", we should not forget about such an important means of conveying information as audio installations of three-dimensional museum objects. These are not only the usual audio guides, but also stationary audio headphones next to a shop window or an object, thanks to which the visitor finds himself in a certain epoch or topic. We consider the most popular multimedia means of communication on the example of interactive expositions of the world's leading museums and justify the need for their use and importance in the formation of the museum space in general.

One of the most popular multimedia tools used in the design of interactive exhibits is an interactive table - a mini-multimedia center that allows multiple interactive applications to interact simultaneously and to carry out the communication process to multiple visitors simultaneously. Topical interactive applications

for museums are mosaics in the form of coins or banknotes; placement of coins in the order of their origin and historical development. They will help to draw visitors' attention to the features and details of the exhibited items. The sloping structure is ideal for exhibitions, museum tours and installations.

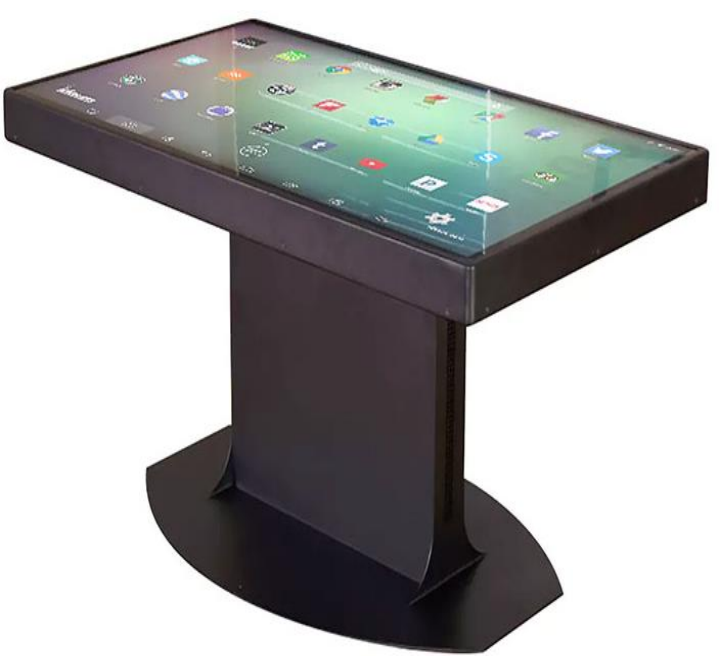

Figure 1. Interactive table

Thus, after the reconstruction and renovation of the museum exposition, the National Museum in Warsaw (Muzeum Narodowe w Warszawie) makes extensive use of interactive tables and selected interactive applications. Today, its visitors have the opportunity to make a mosaic of Byzantine frescoes of the XIII century and thus study the details of the images of saints, consider and compare the technique of drawing, etc. The National Museum in Warsaw was founded in 1862. As the leading museum in Warsaw, it consisted of the collections of a number of other museums and organizations, gradually covering works of various types and genres of art. Today it houses more than 780,000 exhibits. These are collections of ancient and medieval art, paintings by Polish and foreign artists, collections of jewelry, oriental arts, contemporary
Polish art, Polish and European decorative art, as well as many temporary exhibitions [7].

Experience shows that the interactive screen expands the possibilities of presentations, increases the effectiveness of interaction with the audience. The control is usually fulfilled by touching the screen with finger. The sensitive surface of the display responds immediately and transmits data to the control program, which displays the corresponding section or topic on the screen. Thus, the visitor can control the flow of information, choosing interesting topics or sections of the exhibition. On the other hand, the interactive screen can contain visual materials in the form of electronic 3D photo objects. This helps to make the tour of high quality, accessible and understandable to a wide range of visitors.

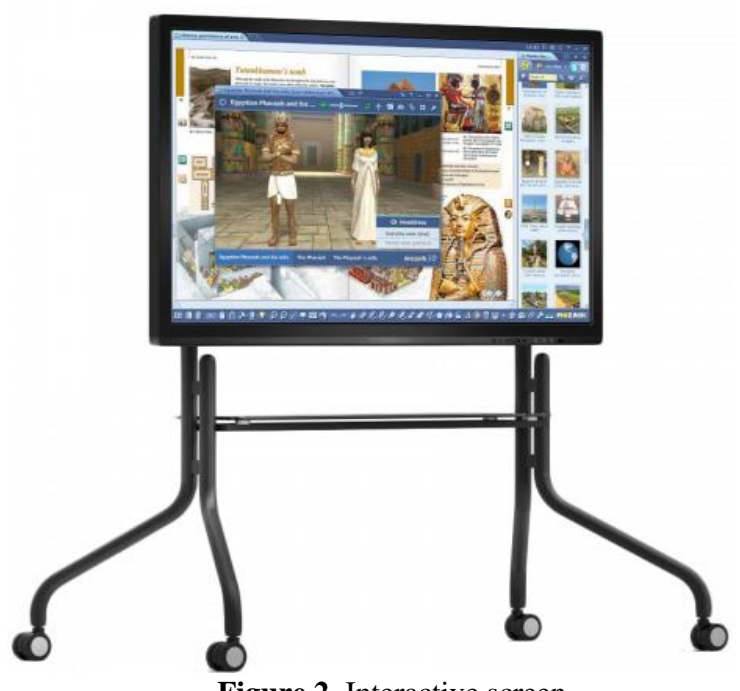

Figure 2. Interactive screen

An example of such interactive solutions is the exposition of the Archaeological Museum of Poznan (Poland). Thanks to the interactive screen, you can get acquainted in detail with a large number of exhibits, learn about their history and operation, as well as get acquainted with virtual exhibits that are not presented in the exhibition or lost for some reason. In the museum you can also put together puzzles of museum objects, answer the questions of the visual photo-questionnaire, etc. It is worth emphasizing that the use of hardware multimedia in the practice exposures allows the visitor to get all the necessary information in an interactive form. At the same time, traditional touch panels are being replaced by Kinekt technology (Kinekt Microsoft). These motion sensors operate in conjunction with a game console [6]. This feature allows controlling what happens on the screen without touching it. On the other hand, modern interactive museum exhibits will use augmented reality technology in the future, which will allow adding virtual objects to the real world.

Another example of multimedia in the exhibition are information kiosks - a kind of "interactive consultants" with a wide range of functional resources and capabilities. They are based on software or a help-interactive system. Information kiosks are search engines with information about exhibits and expositions. They also contain information about the navigation system of exhibition halls. They will advertise and attract potential partners or sponsors. In the days of active use of smartphones and person- 
al computers, the visitor gets used to receiving information instantly and quickly satisfying information services. The use of information kiosks and multimedia technologies, in our opinion, solves the problem of "information loneliness" of the visitor when viewing the classic exhibition.

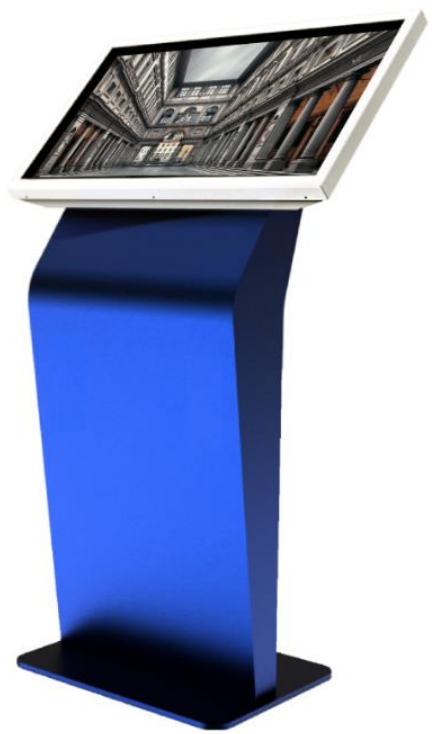

Figure 3. Information kiosk

In particular, such an information kiosk is installed next to the sculpture of David in Florence (Italy). Due to the huge size of the sculpture (five and a half meters), visitors cannot always see the details and explore the masterpiece of Michelangelo. A touch kiosk comes to the rescue, on the screen of which each visitor can "fly around" the sculpture from all angles and sides, and carefully consider all the details of interest. During periodic restorations, the installed kiosk is extremely appropriate and relevant [6].

It is worth noting that the space for educational activities can be a continuation of the exhibition. This is possible if such functionality is present in the museum at the initial stage of its design. For example, in the Melbourne Museum there is a special "learning lab" for the imple- mentation of digital educational projects. This uses interactive walls and a floor with special equipment. During educational events, a flipchart is relevant - a magnetic market board, which is used for lectures, seminars and events. The interactive panel has a QR code that allows using a smartphone to display and store information and transfer it to a personal computer. In this case, there is no need to be distracted by the necessary records and notes.

Today, the nature of cultural communication has changed, the means of visual communication associated with the development of electronic media and media technologies are actively developing. Therefore, it allows us to talk about the need for greater integration of visual aids into traditional museum practice. In addition, with the general information load of society, a bright presentation of information about the exhibit in the form of author's installations using multimedia technologies will create a specific "museum atmosphere" and "effect of immersion" in a particular era. However, the use of technical means only as an end in itself, and not as a means of forming a modern museum space can lead to distraction and reduce the visitor's attention to the museum object. This issue, in our opinion, needs more detailed study and justification.

Conclusions. The article is devoted to the topical problem of introduction of the newest technologies in exposition museum practice and definition of factors of influence on formation and creation of new interactive museum expositions. During the research, the main models of multimedia technologies that can be used in the development of exhibition solutions were successfully identified and characterized. On the example of the analysis of interactive exposition decisions of the European museums the innovative methods of construction of a museum exposition were developed and offered. Prospects for further research are to find an expanded range of models of interactive technologies and multimedia tools that can be used in the construction of an interactive museum exhibition and other factors influencing the formation of modern exhibition space.

\section{REFERENCES}

1. Akoeva N.B. Interactive techniques for working at a museum exposition. The cultural life of the region. 2016. No. 3 (62). P. 113-114.

2. Vaneeva O.V. Integrated use of interactive technologies within the museum space. Museum in the world of culture. The world of culture in the museum. Volume 212. 2015. P. 189196.

3. Vasilyeva L.A. Interaction of visitors with an interactive exposition "room of discoveries". Collection of scientific papers of the State Biological Museum. K.A. Timiryazev. 2006. P. 38-49.

4. Vinogradova A.S. An interactive approach to the formation of a modern exhibition exposition. Design Education in Ukraine: perspectives of development. 2013. No. 2. P. 74 -76.

5. Interactive and multimedia technologies in the museum. URL: http://www.ascreen.ru/projects/type/more.php?id=32 (date of the blast: 02/21/2021).

6. Information kiosks for museums. URL: https://asiaterm.ru/informaczionnyie-kioski/dlya-muzeev/ (date of application: 24.02.2021).

7. Chalaya A. I. Interactivity of space as a modern culturological tendency in the formation of the exposition of exhibitions. Bulletin of the Academy of Marketing and Social Information Technologies. 2016. No. 1. (65). P. 190-198.

8. Muzeum Narodowe w Warszawie. URL: http://www.mnw.art.pl (date of application: 03.02.2021). 